\title{
The molecular mechanism of Vav3 oncogene on upregulation of androgen receptor activity in prostate cancer cells
}

\author{
YIN LIU ${ }^{1}$, XIAOYANG WU ${ }^{1}$, ZHONGYUN DONG ${ }^{2}$ and SHAN LU ${ }^{1}$ \\ Departments of ${ }^{1}$ Pathology and ${ }^{2}$ Medicine, University of Cincinnati College of Medicine, \\ the Metabolic Diseases Institute, Cincinnati, OH 45237, USA
}

Received October 15, 2009; Accepted December 2, 2009

DOI: 10.3892/ijo_00000538

\begin{abstract}
Our previous studies revealed that Vav3 oncogene is overexpressed in human prostate cancer, enhances androgen receptor (AR)-mediated signaling, and may play a role in prostate cancer development and progression. The purpose of this study was to determine the molecular mechanisms responsible for AR activation by Vav3. We found that interaction between $\mathrm{N}$-terminus and $\mathrm{C}$-terminus of $\mathrm{AR}$ is essential for its elevated activity stimulated by Vav3. The DH and $\mathrm{PH}$ domains of Vav3 are involved in direct interaction with AR. Both cytoplasmic and nuclear levels of AR and Vav3 are elevated and their nuclear localization is further stimulated by DHT in androgen-independent LNCaP-AI cells relative to their parental androgen-dependent $\mathrm{LNCaP}$ cells. Vav3 is colocalized with AR, phospho(P)-Akt, and HER2 with a short term stimulation by EGF and DHT. PI3K inhibitor LY294002 blocks colocalization of Vav3 with P-Akt. Consistently, EGF and DHT stimulate Vav3 and AR interaction and enhance PI3K-Akt signaling. Mutation of tyrosines to phenylalanines in the acidic domain or deletion of the $\mathrm{SH} 2$ and SH3 domains significantly enhances Vav3 ability for AR activation, while deletion of the DH domain abolishes this activity. Given that an elevated interaction of Vav3 with AR, P-Akt, and HER2 in both cytoplasm and nucleus upon the short-term of DHT stimulation, our data suggest that Vav3 may enhance non-genomic AR activity via PI3K-Akt signaling in addition to AR transcriptional activity and further support a role in androgen-independent growth in prostate cancer.
\end{abstract}

\section{Introduction}

Vav family proteins are oncogenes and function as quanine nucleotide exchange factor (GEF) for Rho family GTPases $(1,2)$. Among three members (Vav1, Vav2 and Vav3), Vav1 is

Correspondence to: Dr Shan Lu, Department of Pathology, University of Cincinnati College of Medicine, 2120 E. Galbraith Road, Building A, Room 259, Cincinnati, OH 45237, USA

E-mail:shan.lu@uc.edu

Key words: Vav3 oncogene, androgen receptor, prostate cancer, signaling pathway primarily expressed in hematopoietic cells, while Vav2 and Vav3 are more ubiquitously expressed. Vav proteins contain multiple function motifs and are involved in various cellular signaling processes, including cytoskeleton organization, calcium influx, phagocytosis and cell transformation (3). Vav proteins share a common structure, including a $\mathrm{N}$-terminal calponin homology $(\mathrm{CH})$ domain involved in $\mathrm{Ca}^{+2}$ mobilization and transforming activity, an acidic domain (AD) containing three regulatory tyrosines, a Dbl homology (DH) domain with a conserved region that promotes the exchange of GDP for GTP on Rac/Rho GTPases, a pleckstrin homology (PH) domain binding to $\mathrm{PIP}_{3}$ that enables its movement to the inner face of the plasma membrane, two Src-homology 3 (SH3) domains interacting with proteins containing proline-rich sequences, and an Src-homology 2 (SH2) domain interacting with proteins containing phosphorylated tyrosines $(4,5)$. Tyrosine phosphorylation by receptor protein tyrosine kinase or cytoplasmic protein tyrosine kinase is required for Vav protein activation (6).

It has been well documented that AR hypersensitivity contributes to prostate cancer development and progression. Majority of human prostate cancers are AR-positive (7-10). Hormone ablation therapy to compromise AR activity is a major therapeutic modality against advanced prostate cancer $(11,12)$. Recurrent diseases develop resistance to this therapy. Various androgen-independent but AR-dependent mechanisms serve as alternative pathways to support prostate cancer cell growth. For instance, AR mutation and gene amplification are common alterations associated with prostate cancer progression (13-16). Mutations in the ligand binding domain generate a promiscuous AR, which is activated by a broad spectrum of ligands, such as unfavorable ligands and even antagonists $(17,18)$. Coactivators interact with nuclear receptors in a ligand-specific manner and enhance their transcriptional activity (19). Overexpression of coactivators, such as RAC3/SRC3, was found in prostate cancer and involved in the disease progression (20-22). AR can also be activated by phosphorylation mediated via a variety of signaling pathways, such as PI3K-Akt signaling (23). Phosphorylation of AR enhances its nucleus translocation, response to ligand, and recruitment of coactivators and chromatin remodellers and modifiers, resulting in decompact repressive chromatin and expression of target genes (24-27).

AR classically is defined as a ligand-dependent transcription factor to activate transcription of its target genes in 
nucleus, which is known as genomic AR activity (genotropic signal). Recent findings revealed that the classical steroid hormone receptors, including $\mathrm{AR}$, are associated with cell membrane and mediate cell signaling through kinase cascade, defined as non-genomic (non-genotropic) activity (28-30). Non-genomic AR activity is extremely rapid (in minutes rather than hours) and independent of protein synthesis and gene transcription. Non-genomic AR resides in multiprotein complexes in the cytoplasm before ligand binding and nuclear translocation, which allows the productive interaction with molecules, such as Caveolin, MNAR, and Src, in the cytosol at extranuclear-membrane surfaces $(29,31,32)$.

Accumulating evidence has revealed a role of Vav3 oncogene in steroid-related cancers. Recently, others and we found that Vav3 oncogene is overexpressed in androgenindependent prostate cancer cells, enhances AR activity, and stimulates androgen-independent growth in prostate cancer cells (33-35). We further showed that Vav3, as a signal transducer, upregulates AR activity partially via PI3K-Akt signaling (33). The DH domain of Vav3 is essential for AR activation. More importantly, Vav3 is overexpressed in $32 \%$ of human prostate cancer. Targeted overexpression of Vav3 in prostatic epithelium enhances both AR- and NF-kB-mediated signaling pathways leading to development of non-bacterial prostatitis and prostate cancer (36).

Both breast and prostate cancers are steroid-dependent tumors and share a significant similarity in their characteristics and treatment, such as hormone-dependent growth mediated by their corresponding estrogen receptor $\alpha(\mathrm{ER} \alpha)$ and $\mathrm{AR}$, hormone ablation therapy against these steroid-dependent tumors, and subsequent development of hormone resistance $(37,38)$. Therefore, we examined a role of Vav3 in breast cancer. We found that Vav3 is overexpressed in $81 \%$ of human breast cancers, particularly in poorly differentiated lesions (39). Vav3 also complexes with ER $\alpha$, enhances its activity partially via PI3K-Akt signaling, and stimulates growth of breast cancer cells.

The current study is to determine the molecular mechanisms responsible for AR activation by Vav3. We found that the DH and PH domains of Vav3 are involved in direct interaction with $\mathrm{AR}$ and are essential for AR activation. Upon short-term stimulation by EGF and DHT, Vav3 is colocalized with AR, P-Akt, and HER2 in prostate cancer cells. Shortterm of androgen stimulation enhances PI3K-Akt signaling and interaction between Vav3 and AR. There are significant elevated AR and Vav3 in androgen-independent LNCaP-AI cells relative to their parental androgen-dependent LNCaP cells. Our findings suggest that Vav3 complexes with AR and enhances both non-genomic and genomic AR activity via the PI3K-Akt pathway and support a role of Vav3 in androgenindependent growth in prostate cancer cells.

\section{Materials and methods}

Reagents. RPMI-1640 medium was purchased from Invitrogen (Gaithersburg, MD). Fetal bovine serum (FBS) and charcoal/ dextran-treated FBS were purchased from HyClone Laboratories (Logan, UT). Anti-Vav3 antibody was obtained from Upstate Biotechnology (Charlottesville, VA). Antiphospho-Vav3[pY173] antibody was from BioSource
International, Inc. (Camarillo, CA). Anti-P-Akt, Akt, Hsp90, and PARP antibodies were from Cell Signaling Technology (Danvers, MA). Anti-AR and Anti-Vav3 antibodies were obtained from Upstate Biotechnology. Anti-HER2 antibody is from CalBiochem (San Diego, CA). The recombinant AR expressed and purified from baculovirus expression system is a generous gift from Dr Donald McDonnell, Department of Pharmacology and Cancer Biology, Duke University Medical Center.

Cell culture. The human prostate adenocarcinoma cell line LNCaP and cervical carcinoma cell line HeLa were obtained from ATCC (Rockville, MD) and maintained in RPMI-1640 medium supplemented with $10 \%$ FBS (complete medium) at $37^{\circ} \mathrm{C}$ in $5 \% \mathrm{CO}_{2}$. LNCaP-AI cells were maintained in RPMI-1640 medium supplemented with $10 \%$ charcoal/ dextran-treated FBS (stripped medium). Transient transfection experiments were performed in stripped medium.

Plasmids. Plasmids pBEF-Vav3, pHEF-Vav3*, pHEF-Vav3*$\triangle \mathrm{DH}, \mathrm{pHEF}-\mathrm{Vav} 3^{*}-\Delta \mathrm{SH}$, and control vector $\mathrm{pHEF}$ as well as GST-Vav3-DH+PH were detailed in our previous studies $(33,39)$. Vav3- $\Delta \mathrm{SH}$ with deletion of the $\mathrm{SH} 2$ and $\mathrm{SH} 3$ domains was generated by deletion of C-terminal sequence of Vav3 using BamH1 site and then insertion of a linker containing stop codons (5'-GGATCCATAATGAGAGTCGAC-3'). Vav3 constructs with tyrosine mutation in the AD domain were constructed using the QuickChange II site-directed mutagenesis kit (Stratagene, La Jolla, CA). All the mutants were confirmed by sequencing of the final constructs.

Western blot analysis. Western blot analysis was performed as previously described (40). Briefly, aliquots of samples with the same amount of protein, determined using the Bradford assay (BioRad, Hercules, CA), were mixed with loading buffer (final concentrations of $62.5 \mathrm{mM}$ Tris- $\mathrm{HCl}$, $\mathrm{pH} 6.8,2.3 \%$ SDS, $100 \mathrm{mM}$ dithiothreitol, and $0.005 \%$ bromophenol blue), boiled, fractionated in an SDS-PAGE, and transferred onto a $0.45-\mu \mathrm{m}$ nitrocellulose membrane (BioRad). The filters were blocked with $2 \%$ fat-free milk in PBS, and probed with first antibody in PBS containing $0.1 \%$ Tween-20 (PBST) and 1\% fat-free milk. The membranes were then washed 4 times in PBST and incubated with horseradish peroxidase-conjugated secondary antibody (Bio $\mathrm{Rad}$ ) in PBST containing 1\% fat-free milk. After washing 4 times in PBST, the membranes were visualized using the ECL Western blotting detection system (Amersham Co., Arlington Height, IL). For Western blot analysis of Vav3 expression, the first antibody was incubated overnight at $4^{\circ} \mathrm{C}$.

Reporter assay. Cells (105/well) were seeded in 12-well tissue culture plates. Next day, Optifect-mediated transfection was used for the transient transfection assay according to the protocol provided by Invitrogen/Life Technologies, Inc. The cells were then treated with hormone or drugs in stripped medium for $24 \mathrm{~h}$. Subsequently, the cell extracts were prepared and luciferase activity was assessed in a Berthold Detection System (Pforzheim, Germany) using a kit (Promega, Madison, WI) as per the manufacturer's instructions. For each assay, cell extract $(20 \mu \mathrm{l})$ was used and the reaction was started by 
injection of $50 \mu \mathrm{l}$ of luciferase substrate. Each reaction was measured for $10 \mathrm{sec}$ in the Luminometer. Luciferase activity was defined as light units/mg protein.

GST pull down. GST-Vav3-DH+PH and control GST vectors were transformed into BL21 bacteria, respectively (Protein Express Inc., Cincinnati, OH). The transformed bacteria were cultured in L-Broth with addition of $100 \mu \mathrm{M}$ of IPTG to induce GST-fusion protein expression. Then, the bacteria were harvested and subjected to GST fusion protein purification by sonication and using glutathione sepharose $4 \mathrm{~B}$ (Amersham Bioscience).

For pull down reaction, 5-10 $\mu \mathrm{g}$ of GST or GST-Vav3$\mathrm{DH}+\mathrm{PH}$ was incubated with $1 \mathrm{mg}$ of cell extracts from LNCaP cells in a binding buffer $[20 \mathrm{mM}$ of Tris- $\mathrm{HCl}, \mathrm{pH} 7.9$; $300 \mathrm{mM}$ of $\mathrm{KCl} ; 0.05 \%$ of NP-40; $0.2 \mathrm{mM}$ of EDTA; $20 \%$ of glycerol; $1 \mathrm{mM}$ of dithiothritol; $1 \mathrm{mM}$ of phenylmethylsulfonyl fluoride (PMSF), 1X of protease inhibitor cocktail (Roche Diagnostics)] for overnight $(41,42)$. Then, the beads were washed for 5 times in a washing buffer $(20 \mathrm{mM}$ of Tris- $\mathrm{HCl}, \mathrm{pH} 7.9 ; 300 \mathrm{mM}$ of NaCL; $0.01 \%$ of NP-40; $0.2 \mathrm{mM}$ of EDTA; $20 \%$ of glycerol; $0.5 \mathrm{mM}$ of dithiothritol) and boiled in $1 \mathrm{X}$ SDS loading buffer. The proteins in the supernatant were subjected for SDS-PAGE, which was visualized by Coomassie Blue staining. The samples were also subjected to Western blot analysis for AR.

Coimmunoprecipitation assay. One milligram of cell extract was used for each sample. Coimmunoprecipitation was performed in a modified RIPA buffer [50 mM Tris-HCl (pH 7.5), 1\% NP-40, $0.5 \%$ sodium deoxycholate, $0.1 \%$ SDS, $100 \mathrm{mM} \mathrm{NaCl}, 1 \mathrm{mM}$ DTT, $1 \mathrm{mM}$ PMSF, $10 \mu \mathrm{g} / \mathrm{ml}$ of pepstatin, leupeptin, and aprotinin each]. The antibody and protein complexes were precipitated by protein G plus/ protein A agarose beads (Calbiochem, San Diego, CA) at 2,500 $\mathrm{rpm}$ for $5 \mathrm{~min}$. The beads were washed with the modified RIPA buffer 4 times. The protein complexes were subjected to Western blot analysis using anti-AR antibody.

Confocal microscopy analysis. LNCaP cells growing on $12 \mathrm{~mm}$ round cover slide were starved in $1 \%$ stripped medium for $48 \mathrm{~h}$ and then treated with DHT or EGF. Subsequently, the cells were fixed in $3.7 \%$ paraformaldehyde in PBS for 20 min, rinsed with PBS, fixed in cold acetone for $5 \mathrm{~min}$, blocked with $1 \%$ goat serum in PBS for $1 \mathrm{~h}$, post-permeabilized in $0.5 \%$ Triton X-100 in PBS for 5 min. After washing several times, the cells were incubated with first antibody in $1 \%$ normal goat serum in PBS for $1 \mathrm{~h}$, washed with PBS, and incubated with anti-mouse antibody conjugated with fluorescence dye Alexa Fluor 488 (green, Invitrogen, cat\# A21121) or anti-rabbit antibody conjugated with far-red-fluorescent Alexa Fluor 633 dye (Invitrogen, cat\# A21071). After washing in PBS for $30 \mathrm{~min}$, the cells were stained with $100 \mu \mathrm{M}$ of $4^{\prime}, 6-$ diamidino-2-phenylindole (DAPI) for $5 \mathrm{~min}$. Then the slides were embedded in anti-fade medium and mounted on a light microscopy slide.

Mammalian two-hybrid assay. HeLa cells (105/well) were seeded in 12-well tissue culture plates. Next day, Optifectmediated transfection was used to transfect the cells with
A.
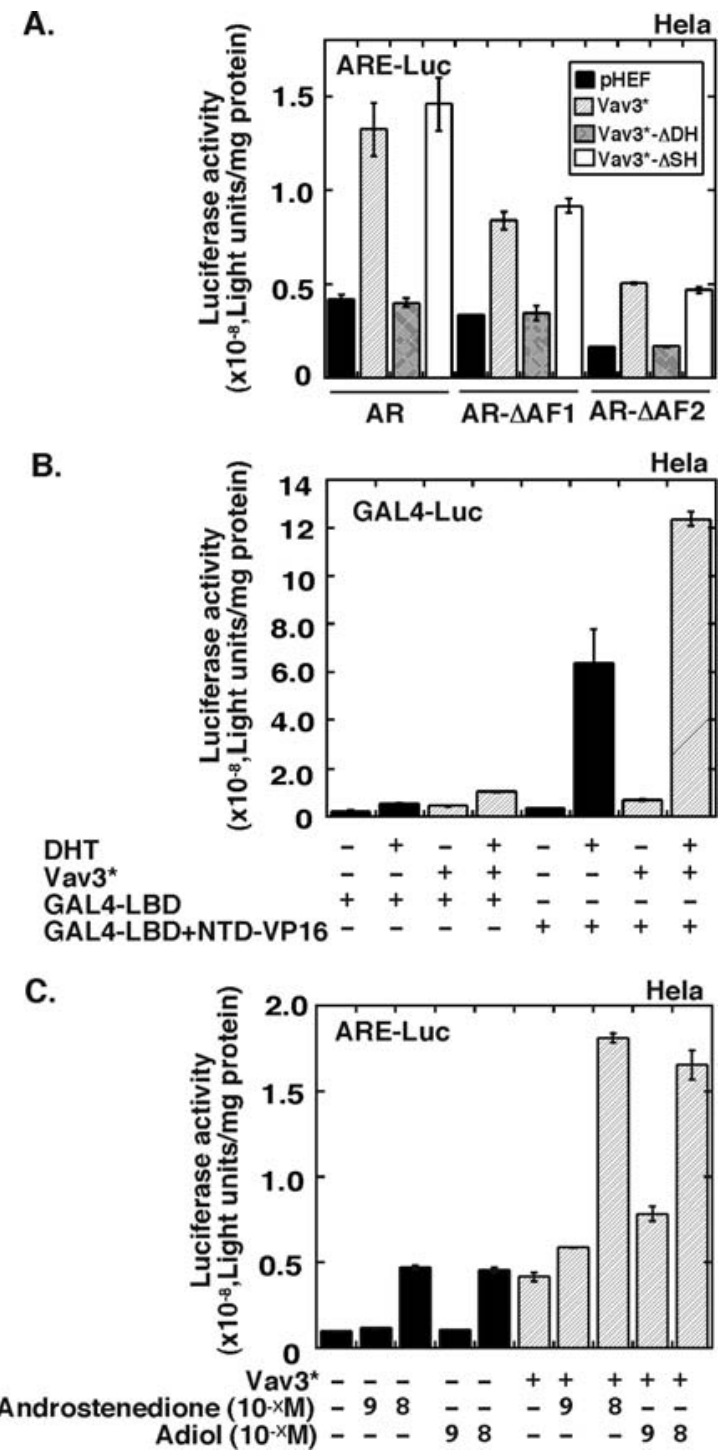

Figure 1. Vav3 activates AR. (A) HeLa cells were transiently cotransfected with pGL3-ARE-E4-Luc $(0.5 \mu \mathrm{g})$ and expression vectors AR, AR- $\triangle \mathrm{AF} 1$ or AR- $\Delta$ AF2 (50 ng), and Vav3*, Vav3 ${ }^{*}-\Delta S H$, or Vav3*- ${ }^{*}$ DH (200 ng), respectively. Then, the cells were treated with DHT $\left(10^{-9} \mathrm{M}\right)$ in stripped medium for $24 \mathrm{~h}$. (B) HeLa cells were transiently cotransfected with GAL4Luc $(0.5 \mu \mathrm{g})$ and expression vectors for Vav3* (200 ng), GAL4-LBD (200 ng), and GAL4-LBD+NTD-VP16 (200 ng), respectively. Then, the cells were treated with DHT $\left(10^{-9} \mathrm{M}\right)$ in stripped medium for $24 \mathrm{~h}$. (C) HeLa cells were transiently cotransfected with pGL3-ARE-E4-Luc $(0.5 \mu \mathrm{g})$ and expression vectors for AR (50 ng) and Vav3* (100 ng). Then, the cells were treated with androstene-3B, 17ß-diol (Adiol) and androstenedione in stripped medium for $24 \mathrm{~h}$. Luciferase assay was performed according to a standard protocol with Renilla luciferase as an internal control. Data are presented as the mean $( \pm \mathrm{SD})$ of duplicate values of a representative experiment that was independently repeated 5 times.

luciferase reporter driven by the GAL4 binding site and expression vectors for GAL4-LBD containing GAL4 DNAbinding domain fused with LBD of AR, and/or NTD-VP16 containing VP16 transactivation domain fused with NTD of AR. The cells were then treated with hormone in stripped medium for $24 \mathrm{~h}$. Subsequently, the cell extracts were prepared and luciferase activity was assessed in a Berthold Detection System (Pforzheim, Germany) using a kit (Promega, Madison, WI). 

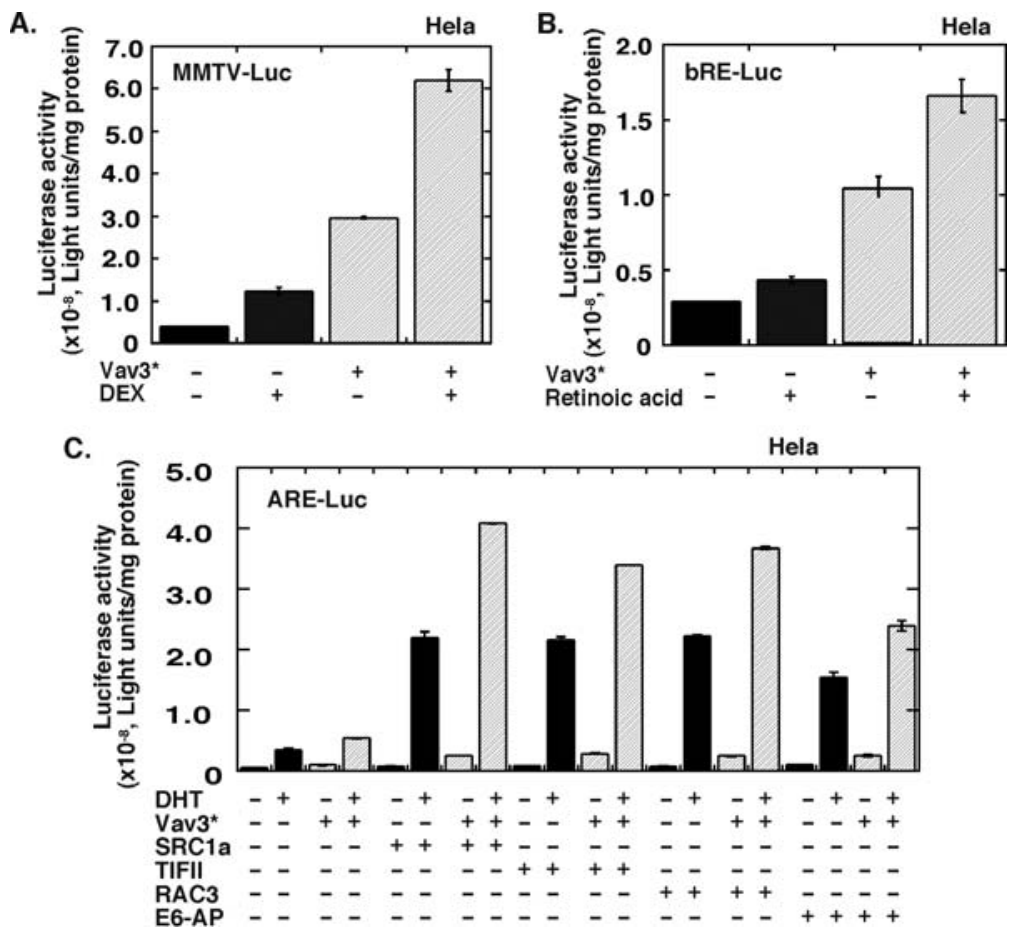

Figure 2. Vav3 enhances activities of GR and RAR and shows an additive effect with other coactivators for AR activation. (A and B) HeLa cells (10 5 cells/ well in 12-well plate) were cotransfected with MMTV-Luc $(0.5 \mu \mathrm{g})$ and GR expression vector (50 ng) (A) or retinoic acid response element (bRE)-Luc (0.5 $\mu \mathrm{g})$ and RAR/RXR expression vectors (25 $\mathrm{ng}$ each) (B), as well as expression vector (200 ng) for Vav3* or empty vector pHEF, respectively. Then, the cells were treated with Dex (A) or retinoic acid (B) $\left(10^{-8} \mathrm{M}\right)$ for $24 \mathrm{~h}$. (C) HeLa cells were cotransfected with pGL3-ARE-E4-Luc $(0.5 \mu \mathrm{g})$ and expression vector $(50 \mathrm{ng})$ for $\mathrm{AR}$, as well as expression vectors (100 ng) for Vav3*, SRC1a, TIFII, RAC3/SRC3, or E6-AP, respectively. Then, the cells were treated with DHT (10-9 $\mathrm{M})$ for $24 \mathrm{~h}$. Luciferase assay was performed according to a standard protocol with Renilla luciferase as an internal control. Data are presented as the mean $( \pm \mathrm{SD})$ of duplicate values of a representative experiment that was independently repeated 5 times.

Isolation of cytoplasmic and nuclear extracts. The cells were trypsinized from Three P100 plates, washed with cold PBS, and resuspended in $5 \mathrm{ml}$ of hypotonic buffer A [10 $\mathrm{mM}$ Tris$\mathrm{HCl}$ (pH 7.4), $10 \mathrm{mM} \mathrm{NaCl}, 6 \mathrm{mM} \mathrm{MgCl}_{2}, 1 \mathrm{mM}$ EDTA ( $\mathrm{pH}$ 8.0)] and incubated on ice for $5 \mathrm{~min}$. Then, the cells were centrifuged at 1,500 rpm for $5 \mathrm{~min}$ and resuspended in 150-250 $\mu \mathrm{l}$ of hypotonic buffer B [10 mM Tris- $\mathrm{HCl}(\mathrm{pH} 7.4)$, $10 \mathrm{mM} \mathrm{NaCl}, 6 \mathrm{mM} \mathrm{MgCl}$, 1 mM EDTA (pH 8.0), $1 \mathrm{mM}$ dithiothreitol (DTT), $1 \mathrm{mM}$ phenylmethylsulfonyl fluoride (PMSF), 1X protease inhibitor cocktail (x100)]. The cells were disrupted by being sheared using an Eppendorf homogenizer for 25 strokes. Nuclei were collected by a 20 -sec centrifugation at $12,000 \mathrm{x} \mathrm{g}$. The supernatant was removed and cleared by centrifugation at $12,000 \times \mathrm{g}$ for $10 \mathrm{~min}$ at $4^{\circ} \mathrm{C}$, which was cytoplasmic extract. The nuclei pellet was washed once with hypotonic buffer A, resuspended in 150-250 $\mu \mathrm{l}$ of nuclei lysis buffer [20 mM Tris- $\mathrm{HCl}(\mathrm{pH} 7.8), 420 \mathrm{mM}$ $\mathrm{NaCl}, 25 \%$ glycerol, $1.5 \mathrm{mM} \mathrm{MgCl}, 0.2 \mathrm{mM}$ EDTA, $1 \mathrm{mM}$ dithiothreitol, $1 \mathrm{mM}$ PMSF, $1 \mathrm{X}$ protease inhibitor cocktail (x100)], and rocked at $4^{\circ} \mathrm{C}$ for $30 \mathrm{~min}$. Intact nuclei were removed by centrifugation at $12,000 \mathrm{x}$ g for $3 \mathrm{~min}$ at $4^{\circ} \mathrm{C}$, and the supernatant was recovered and called the nuclear extract.

\section{Results}

Vav3 modulates AR activity via both $N$-terminal and $C$ terminal domains. Previously we have shown that the $\mathrm{DH}$ domain of Vav3 is essential for AR activation (33). AR is a unique steroid hormone receptor as compared with others in that its $\mathrm{N}$-terminus and $\mathrm{C}$-terminus interaction is required for full AR activity upon androgen stimulation $(24,43)$. We determined whether the function of $\mathrm{N}$-terminal domain (NTD) of AR containing activation function 1 (AF1) and Cterminal domain or ligand binding domain (LBD) including activation function 2 (AF2) are involved in Vav3 impact on AR transactivation activity. HeLa cells were transiently cotransfected with an androgen response element (ARE)driven luciferase reporter, expression vectors for Vav3 constructs, and wild-type or truncated AR (33). AR- $\triangle A F 1$ is AR with NTD deletion and AR- $\triangle A F 2$ is AR with LBD deletion. As shown in Fig. 1A, constitutive active Vav3* and Vav3*- $\Delta$ SH enhance the activity of both wild-type and truncated AR, while Vav3* ${ }^{*}-\Delta \mathrm{DH}$ has no effect on activity of either wild-type AR or its mutants. These data are consistent with our previous finding (33), indicating that the $\mathrm{DH}$ domain of Vav3 is critical for AR activation.

We then determined whether $\mathrm{N}$-terminus and $\mathrm{C}$-terminus interaction is essential for AR activation by Vav3 in the mammalian two-hybrid assay. HeLa cells were transiently cotransfected with luciferase reporter driven by the GAL4 binding site and expression vectors for Vav3*, GAL4-LBD containing GAL4 DNA-binding domain fused with LBD of AR, and/or NTD-VP16 containing VP16 transactivation domain fused with NTD of AR. Fig. 1B shows that GAL4LBD has a low basal activity and a weak response to androgen 
A.

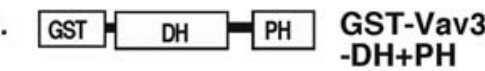

B.

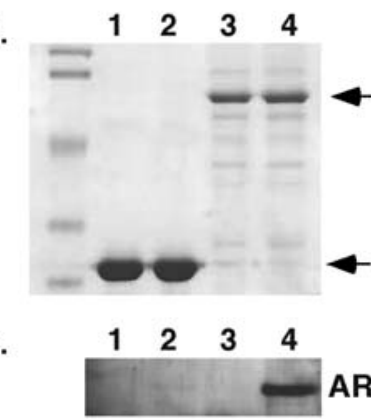

D.

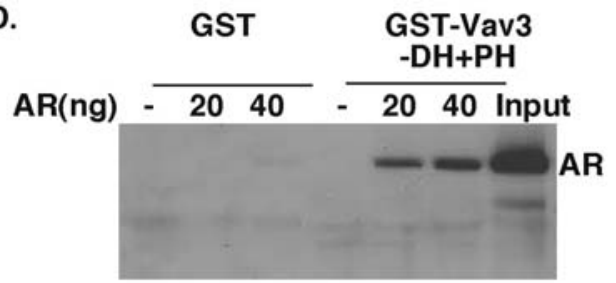

E.

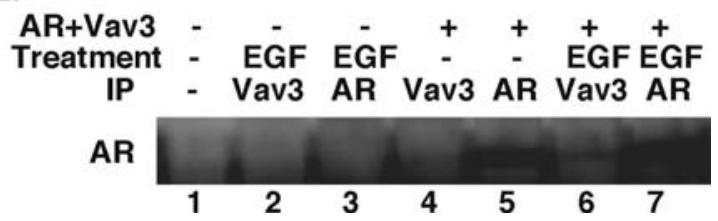

Figure 3. Vav3 forms directly complexes with AR. (A) GST-Vav3-DH+PH fusion protein. (B) GST-Vav3-DH+PH (lane 3 and 4) and control GST (lane 1 and 2) were subjected to pull down reaction in the absence (lane 1 and 3) and presence (lane 2 and 4 ) of cell extract derived from LNCaP cells. The samples were fractionated in SDS-PAGE and stained with Coomassie Blue. (C) The same samples were subjected to Western blot analysis for AR. (D) GST-Vav3$\mathrm{DH}+\mathrm{PH}$ (lane 4, 5 and 6) and control GST (lane 1, 2 and 3) were subjected to pull down reaction using purified AR. The samples were fractionated in SDSPAGE and subjected to Western blot analysis for AR. (E) HeLa cells were transiently transfected with expression vectors for Vav3 and AR in stripped medium without or with EGF stimulation $(100 \mathrm{ng} / \mathrm{ml})$. The cell extracts were used for coimmunoprecipitation with either anti-Vav3 or anti-AR antibody, followed by Western blot analysis using either anti-AR antibody.

stimulation leading to luciferase reporter gene expression. Vav3* stimulates GAL4-LBD activity. Cotransfection of NTD-VP16 and GAL4-LBD significantly enhances reporter gene expression in response to androgen stimulation, which is further stimulated by Vav3*. This experiment confirms that androgen acts as a molecular switch leading to $\mathrm{N}$-terminus and $\mathrm{C}$-terminus interaction, which is required for full activity of AR. Both NTD and LBD are involved in Vav3 regulation of AR activity.

Vav3 enhances AR activity in response to biosynthetic intermediates of testosterone. To determine whether Vav3 overexpression enhances AR activity stimulated by unfavorable ligands, we examined the role of Vav3 for AR activation in response to the stimulation by androgen precursor, such as androstene-3ß, 17ß-diol (Adiol), dehydroepiandrosterone (DHEA), and androstenedione. Vav3 dose-dependently enhances AR activity in response to stimulation by androstenedione and adiol (Fig. 1C), but not DHEA (data not shown). Transactivation of AR by androstenedione and adiol can not be attributed to the conversion of these hormone intermediates to testosterone and dihydrotestosterone, because HeLa cells are cervical cancer cells and lack the enzymes for androgen biosynthesis. Therefore, Vav3 enhances AR activity stimulated not only by androgens but also by androgen biosynthetic intermediates androstenedione and adiol. These data suggest that overexpression of Vav3 leads to hyperactive AR at the sub-physiological level of androgen or androgen precursors and may play a role in androgen-independent growth.

Vav3 enhances activities of nuclear receptors as well as coactivators. Next, we determined whether Vav3 enhances activity of other members in nuclear receptor superfamily in addition to AR and estrogen receptor (ER). As shown in Fig. 2, Vav3* enhances both basal and ligand-stimulated activities of glucocorticoid receptor (GR) (Fig. 2A), retinoic acid receptor (RAR) (Fig. 2B), as well as progesterone receptor
(PR) (data not shown). Furthermore, Vav3* shows an additive effect for AR activation with other coactivators, such as SRC1, TIFII, RAC3/SRC3, and E6-AP (Fig. 2C). These data suggest that Vav3 is possibly a master regulator for nuclear receptor superfamily. Since mutation in Vav3 gene has not been identified at this time, enhanced activities of nuclear receptors are mainly dependent on the elevated level of Vav3 protein in a tissue-specific fashion $(33,39)$.

Vav3 forms complexes with AR via the $D H$ and $P H$ domains. Vav family proteins have been shown to form a complex with transcription factors and regulate gene expression $(44,45)$. The $\mathrm{DH}$ domain of Vav3 contains three consensus sequences of the LXXLL motifs or NR boxes, which have been well characterized and involved in interaction with nuclear receptors (39). Our previous studies showed that the DH domain of Vav3 is essential for AR activation $(33,36)$ and that the $\mathrm{DH}$ and $\mathrm{PH}$ domains of Vav3 complexes with $\mathrm{ER} \alpha$ and enhances ER $\alpha$ activity (39).

To further elucidate the molecular mechanisms potentially responsible for AR activation by Vav3, GST pull down experiment was performed to determine the interaction between the $\mathrm{DH}$ and $\mathrm{PH}$ domains of Vav3 and AR. LNCaP cell extract was incubated with immobilized GST-Vav3$\mathrm{DH}+\mathrm{PH}$, a GST fusion protein including the $\mathrm{DH}$ and $\mathrm{PH}$ domain of Vav3 (Fig. 3A). The pull down samples were fractionated by SDS-PAGE (Fig. 3B) and subjected to Western blot analysis for AR. As shown in Fig. 3C, GST-Vav3-DH+PH complexes with AR. Consistently, GST-Vav3-DH+PH, but not GST, forms complexes with purified AR (Fig. 3D), suggesting that Vav3 interacts with AR directly.

Coimmunoprecipitation analysis was then performed to confirm Vav3 and AR interaction upon EGF stimulation. HeLa cells were transiently cotransfected with Vav3 and AR expression vectors without or with EGF stimulation. The cell extracts from these cells were subjected to coimmunoprecipitation using an anti-Vav3 or anti-AR antibodies followed by immune blot analysis using an anti-AR antibody. We 


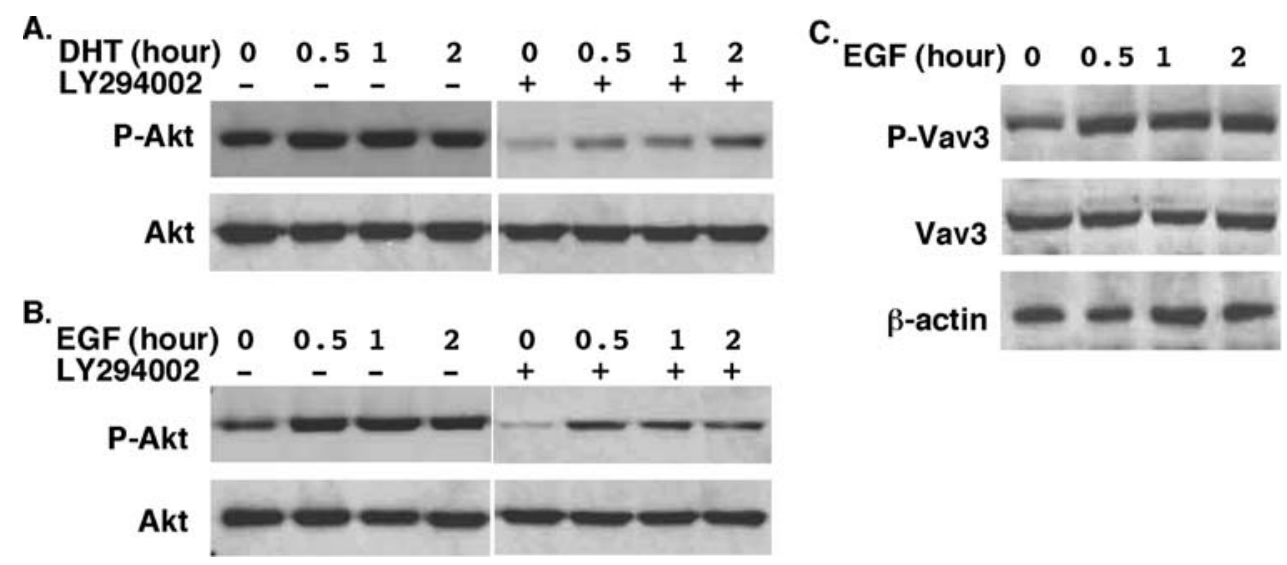

Figure 4. Determination of Akt and Vav3 phosphorylation upon DHT and EGF stimulation. LNCaP cells were starved in $1 \%$ stripped medium for 48 h and then stimulated with DHT (A) and EGF (B and C) as indicated time without or with LY294002 (10 $\mu$ M) for $2 \mathrm{~h}$. Subsequently, the cell extracts were prepared and subjected to Western blot analysis using anti-Akt, anti-phospho-Vav3[pY173], anti-Vav3 and anti-phospho-Akt antibodies, respectively.

A.

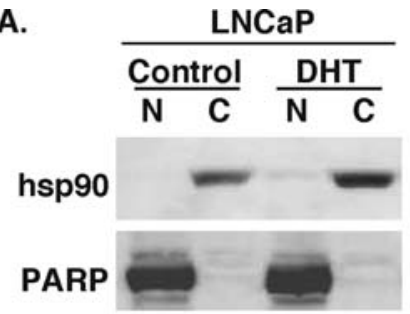

B.

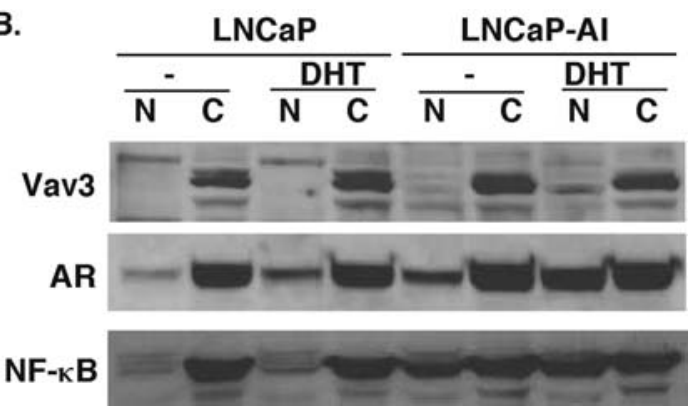

Figure 5. Determination of Vav3, AR, and NF-кB subcellular localization. (A) The nuclear (N) and cytoplasmic (C) extracts were isolated and characterized with hsp90 as a cytoplasmic extract marker and PARP as a nuclear extract marker. (B) The nuclear and cytoplasmic extracts (50 $\mu \mathrm{g}$ ) were isolated from LNCaP and LNCaP-AI cells without or with DHT $\left(10^{-9} \mathrm{M}\right)$ stimulation for overnight and subjected to Western blot analysis for Vav3, AR, and NF- $\mathrm{B}$.

found that there is an elevated interaction between Vav3 and AR upon EGF stimulation relative to control samples (Fig. 3E; lane 6 and 7 vs. lane 4 and 5), while no interaction was detected in the sample without Vav3 and AR expression (Fig. 3E; lane 2 and 3).

Determination of Akt and Vav3 phosphorylation upon DHT and EGF stimulation. It has been well documented that PI3K-Akt signaling enhances both genomic and non-genomic activities of AR (28-30). We first determined the EGF and DHT signal via the PI3K-Akt pathway in our system and found that Akt phosphorylation is moderately enhanced upon short-term of DHT and EGF stimulation (Fig. 4A and B). This DHT-and EGF-induced Akt phosphorylation is significantly enhanced in the cells pretreated with PI3K inhibitor LY294002. Since tyrosine phosphorylation at the acidic domain, including tyrosine 173, activates Vav3 (6), we examined Vav3 phosphorylation at tyrosine 173 upon DHT and EGF stimulation. Western blot analysis using an antiphospho-Vav3[pY173] antibody showed that EGF treatment, but not DHT (data not shown), induces a moderate phosphorylation of Vav3 in LNCaP cells (Fig. 4C). Given that there are many tyrosine phosphorylation sites in Vav3, those tyrosines may be also subjected to regulation of phosphorylation upon EGF stimulation leading to full Vav3 activity. We did not observe Vav3 phosphorylation stimulated by DHT, implicating that Vav3 may be upstream of nongenomic AR in the signal transduction pathway.

Subcellular localization of Vav3. Next, the subcellular localization of Vav3, AR, and NF-kB (Rel A) proteins were determined. The nuclear and cytoplasmic extracts were isolated and characterized with hsp90 as a cytoplasmic extract marker and PARP as a nuclear extract marker (Fig. 5A). Western blot analysis revealed that Vav3, AR, and NF-кB proteins are predominantly localized in cytoplasm in both androgen-independent LNCaP-AI cells and their parental androgen-dependent LNCaP cells (Fig. 5B). Consistent with our previous observation, Vav3, AR, and NF- $\mathrm{kB}$ proteins, specifically nuclear proteins, are elevated in LNCaP-AI cells relative to LNCaP cells and DHT further stimulates their nuclear localization (33) (Fig. 5B). These data support the notion that Vav3 via PI3K-Akt signaling enhances both AR and NF-кB-mediated pathways $(36,46-48)$.

Colocalization of Vav3 with AR, P-Akt, and HER2 upon DHT and EGF stimulation. Confocal analysis was performed to determine the interaction of Vav3 with AR, P-Akt, or HER2 upon androgen or EGF stimulation in LNCaP cells. Immune staining revealed that Vav3 (red) is present in the cytoplasm 


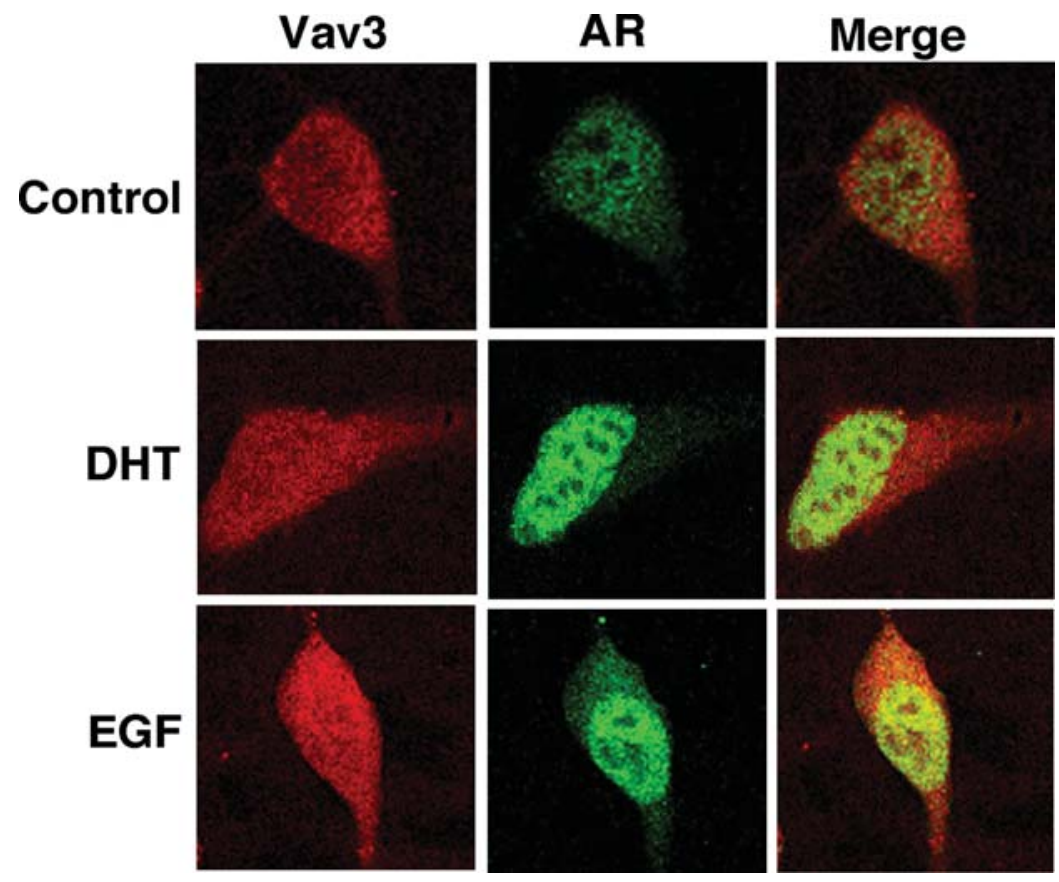

Figure 6. Colocalization of Vav3 (red) and AR (green). LNCaP cells were cultured in $1 \%$ stripped medium for $48 \mathrm{~h}$ and then treated with $\mathrm{DHT}\left(10^{-8} \mathrm{M}\right)$ or EGF $(100 \mathrm{ng} / \mathrm{ml})$ for $2 \mathrm{~h}$. Subsequently, the cells were subjected to confocal analysis by Vav3 labeled with red fluorescence dye or AR labeled with green fluorescence dye

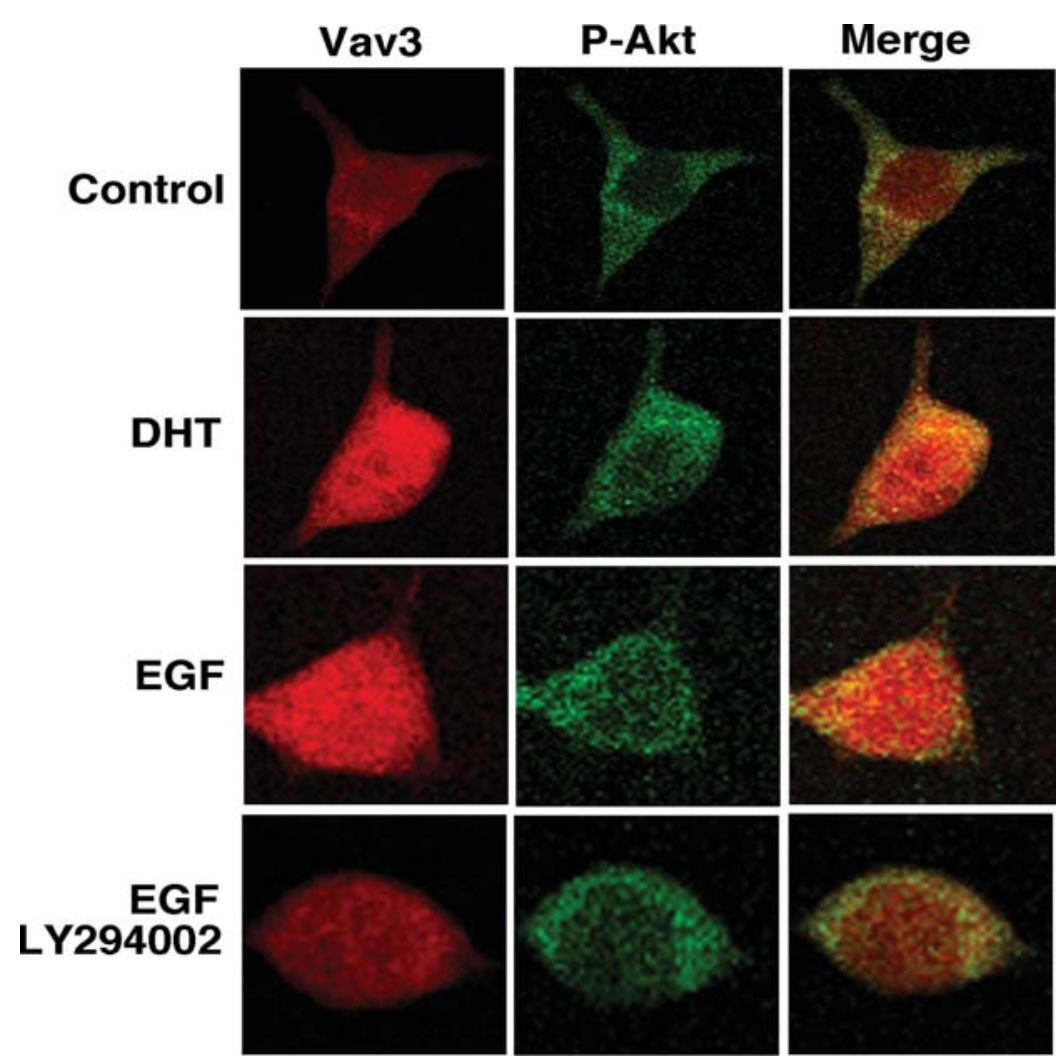

Figure 7. Colocalization of Vav3 (red) and P-Akt (green). LNCaP cells were cultured in $1 \%$ stripped medium for $48 \mathrm{~h}$ and then treated with DHT ( $\left.10^{-8} \mathrm{M}\right)$ or EGF $(100 \mathrm{ng} / \mathrm{ml})$ for $2 \mathrm{~h}$ without or with LY294002 $(10 \mu \mathrm{M})$ pretreatment for $2 \mathrm{~h}$. Subsequently, the cells were subjected to confocal analysis by Vav3 labeled with red fluorescence dye or P-Akt labeled with green fluorescence dye.

and sometimes to a lesser extent in the nucleus. There is a significant nucleus localization of AR (green) upon DHT or EGF stimulation (Fig. 6). There is a significant colocalization (yellow) between Vav3 and AR in both nucleus and cytoplasm upon EGF stimulation. A moderate colocalization between Vav3 and AR was found upon DHT stimulation, especially in cytoplasm, which may be due to significant nuclear localization of AR. 


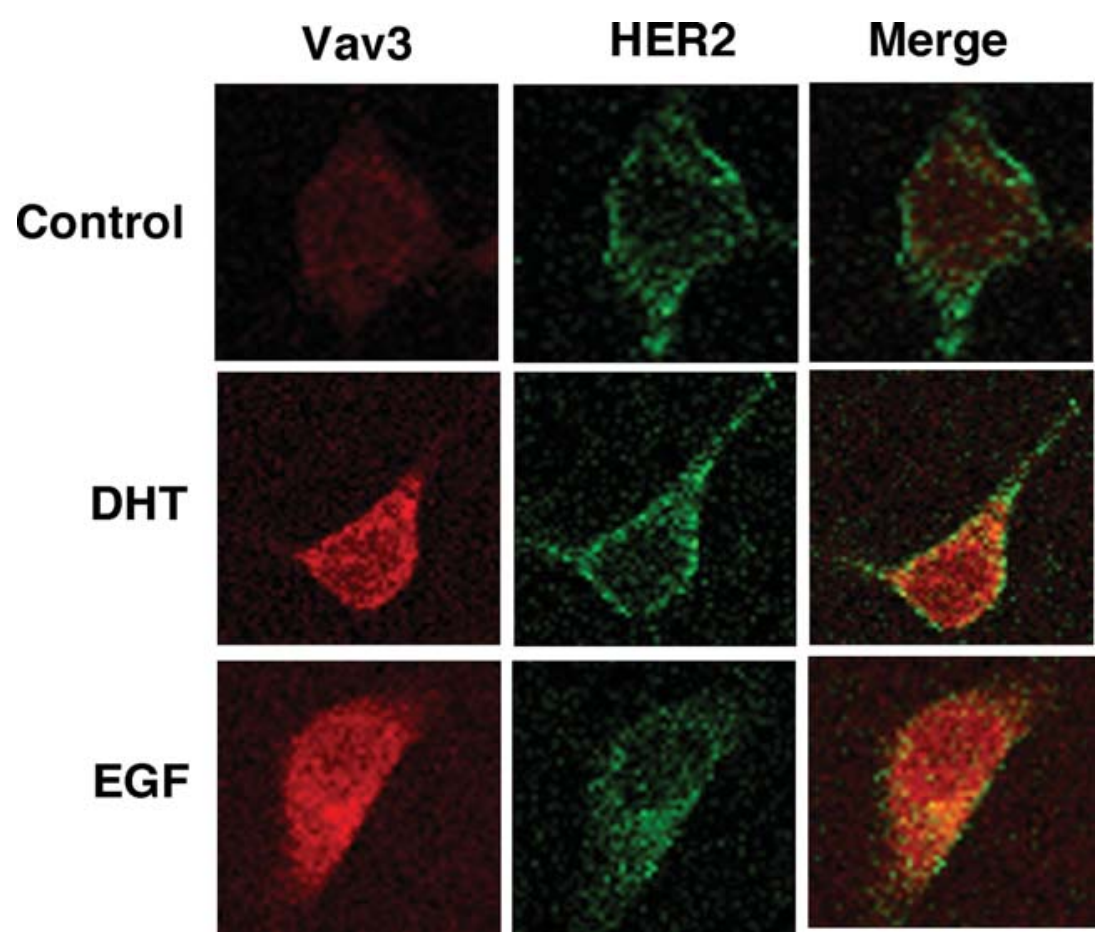

Figure 8. Colocalization of Vav3 (red) and HER2 (green). LNCaP cells were cultured in $1 \%$ stripped medium for $48 \mathrm{~h}$ and then treated with DHT (10-8 $\mathrm{M}$ ) or EGF $(100 \mathrm{ng} / \mathrm{ml})$ for $2 \mathrm{~h}$. Subsequently, the cells were subjected to confocal analysis by Vav3 labeled with red fluorescence dye or HER 2 labeled with green fluorescence dye.

P-Akt (green) is predominantly localized in cytoplasm (Fig. 7). Upon DHT and EGF stimulation, there is a significant colocalization (yellow) between Vav3 (red) and P-Akt in cytoplasm. Pretreatment of LY294002 attenuates the colocalization between Vav3 and P-Akt. HER2 (green) is associated with cell membrane (Fig. 8). Upon DHT and EGF stimulation, there is a significant colocalization (yellow) between Vav3 (red) and HER2 in cell membrane and cytoplasm to a lesser degree. These data implicate that HER2 and Vav3 may be partially internalized upon stimulation by DHT and EGF. These data reveal that treatment with DHT or EGF for a short term enhances Vav3 interaction with AR, P-Akt, and HER2 in both the nucleus and cytoplasm, indicating that Vav3 overexpression may enhance both nongenomic and genomic AR activity via PI3K-Akt signaling.

Mutation analysis of Vav3 function for AR activation. The $\mathrm{DH}$ domain of Vav3 is essential for AR and ER $\alpha$ activation $(33,39)$ and is involved in the complex with these receptors (Fig. 3). To dissect functional domain of Vav3 involved in AR activation, a series of Vav3 protein with deletion and/or point mutation were generated (Fig. 9A). Construct Vav3Y160+173F contains full length Vav3 with tyrosines 173 and 160 in the AD domain being replaced by phenylalanine. Vav3- $\Delta \mathrm{SH}$ is Vav3 with deletion of both $\mathrm{SH} 2$ and $\mathrm{SH} 3$ domains at the $\mathrm{C}$-terminus. Vav3- $\Delta \mathrm{SH}-\mathrm{Y} 160+173 \mathrm{~F}$ contains deletion of the $\mathrm{SH} 2$ and $\mathrm{SH} 3$ domains as well as mutation in tyrosines 173 and 160. Tyrosine 173 and 160 mutation will abolish the tyrosine phosphorylation in the AD domain, while deletion of both $\mathrm{SH} 2$ and $\mathrm{SH} 3$ domains will block the anchorage of Vav3 in the intracellular domain of receptor protein tyrosine kinase (RPTK), such as EGFR.
We found that tyrosine mutations significantly enhance Vav3 activity for AR activation, while deletion of the $\mathrm{SH}$ domains moderately enhances Vav3 activity (Fig. 9B and C). Vav3- $\Delta$ SH-Y3xF, including deletion of SH2 and SH3 domains and a mutation at all three tyrosine residues (tyrosine $141,160,173)$ in the AD domain, shows the highest activity for AR activation (data not shown). These data suggest that the tyrosine to phenylalanine mutation may release the inhibitory effect of the N-terminal domain, leading to an elevated activity of Vav3 for AR activation. EGF stimulation further enhances the activities of these Vav3 mutants for AR activation, suggesting that additional tyrosine sites are also subjected to regulation by phosphorylation and modulation of Vav3 activity.

Among all Vav3 mutants, Vav3* and Vav3*- ${ }^{*} \mathrm{SH}$ are the most potent AR activators at both basal level and in response EGF stimulation (Fig. 9A and C). Consistent with our previous findings $(33,39)$, deletion of the DH domain abolishes Vav3 activity for AR activation. These data suggest that $\mathrm{N}$-terminus of Vav3 may block the $\mathrm{DH}$ and $\mathrm{PH}$ domains for interacting with AR and nuclear localization signaling (39). Furthermore, deletion of the $\mathrm{SH} 2$ and $\mathrm{SH} 3$ domains responsible for interaction with RPTR confers Vav3 an elevated activity for AR activation, implicating that a coactivator activity of Vav3 for AR.

\section{Discussion}

The current study is a continuation of our previous research in determination of the molecular mechanisms responsible for AR activation by Vav3 and potential roles of Vav3 in steroidrelated cancers. We found that Vav3 enhances activities of 

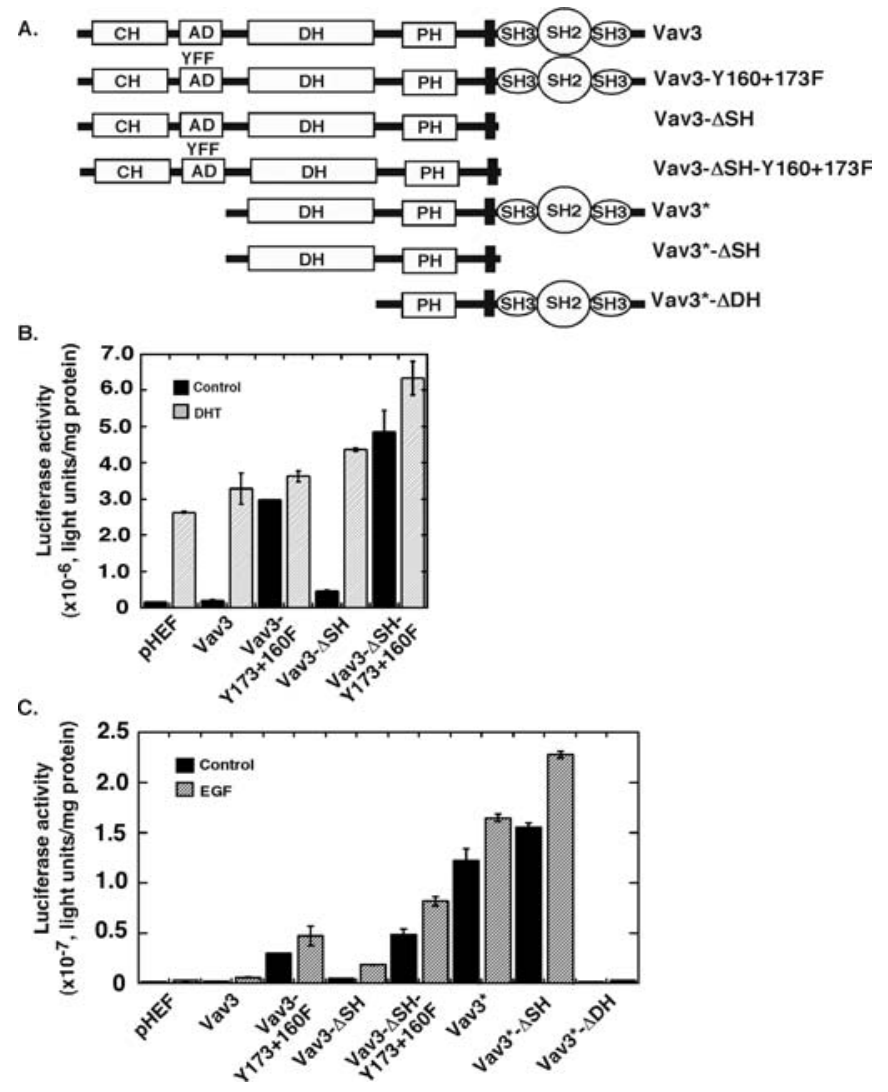

Figure 9. Mutation analysis of Vav3 activity for AR activation. (A) Vav3 constructs with deletion and point mutation. (B and C) LNCaP cells were cotransfected with PSA-Luc $(0.5 \mu \mathrm{g})$ and Vav3 expression vector (200 ng), respectively. Then, the cells were treated with DHT $\left(10^{-8} \mathrm{M}\right)(\mathrm{B})$ or EGF $(100 \mathrm{ng} / \mathrm{ml})(\mathrm{C})$ for $24 \mathrm{~h}$, followed by luciferase assay. Renilla luciferase was used an internal control. Data are presented as the mean $( \pm \mathrm{SD})$ of duplicate values of a representative experiment that was independently repeated for 5 times.

both steroid and non-steroid hormone receptors and shows an additive effect with other coactivators in upregulation of AR activity. $\mathrm{N}$-terminus and $\mathrm{C}$-terminus interaction of $\mathrm{AR}$ is essential for full transcription activity stimulated by Vav3. The DH and PH domains of Vav3 are involved in direct interaction with AR. We also found that Vav3 is colocalized with AR, P-Akt, and HER2 with short-term stimulation by DHT and EGF. Mutation of tyrosines to phenylalanines in the AD domain or deletion of the $\mathrm{SH} 2$ and $\mathrm{SH} 3$ domains enhances Vav3 ability for AR activation. Given that an elevated interaction of Vav3 with AR, P-Akt, and HER2 in both cytoplasm and nucleus upon short-term of DHT stimulation, our data suggest that Vav3 may enhance both nongenomic and genomic AR activity via PI3K-Akt signaling, supporting a role in androgen-independent growth in prostate cancer.

Non-genomic AR activity has been shown to contribute to androgen-independent growth in prostate cancer $(28,49,50)$. It was reported that AR directly interacts with caveolin-1 in plasma membrane structures called caveolae, an invaginated form of membrane microdomain that are commonly referred as 'lipid rafts' (31). Membrane associated AR was identified within the cholesterol-rich 'lipid raft' membrane fraction to sequester signaling partners in multiple pathways. Nongenomic AR also signals cell survival in lipid rafts in the absence of caveolins in human prostate cancer cells $(49,50)$. In addition, non-genomic activity of AR has been demonstrated to contribute to androgen-independent growth by signaling through the PI3K-Akt pathway $(49,50)$ or in the form of cytoplasmic Src-AR-ER complex (27-29). Src tyrosine kinase contains $\mathrm{SH} 2$ and $\mathrm{SH} 3$ domains and is activated by receptor protein tyrosine kinase. Src-AR interaction in response to EGF stimulation signals through the MAPKmediated pathway, leads to elevated AR phosphorylation and nucleus localization, and is associated with androgenindependent phenotype in prostate cancer cells. We found that Vav3 directly forms a complex with AR. More interestingly, Vav3 is colocalized with AR, P-Akt, and HER2 in both cytoplasm and nucleus upon brief DHT and EGF stimulation. These findings implicate that Vav3 may enhance both non-genomic AR and non-genomic activity via PI3KAkt signaling.

Vav3 is an oncogene identified in cell transformation experiments (3). Vav3 is activated upon ligand stimulation of EGF, insulin, Ros, and IGF receptors and physically associates with a variety of signaling molecules, including Rac1, Cdc42, PI3K, Grb2, and PLC- $\gamma$, leading to alteration in cell morphology and cell transformation (51). Overexpression of Vav3 leads to PI3K activation and focus formation in NIH3T3 cells (52). In contrast, blocking PI3K activation by PTEN and LY294002 inhibits Vav3-induced cell transformation. Furthermore, it has been shown that Vav3 mutant with $\mathrm{N}$-terminal domain deletion including the $\mathrm{AD}$ domain is a constitutive active form and has much stronger oncogenic effect relative to wild-type Vav3 (53). It was proposed that in the non-phosphorylation state, Vav is folded, which is achieved by binding of the tyrosines in the $\mathrm{AD}$ domain to the $\mathrm{DH}$ domain and binding of the $\mathrm{CH}$ domain to the $\mathrm{C} 1$ region (6). Upon phosphorylation of the tyrosines in the AD domain, the folding is opened and the DH domain is exposed. Thus, Vav protein is activated and interacts with substrate proteins, and the PH domain is exposed for PIP3 binding. Burnstein's group showed that the $\mathrm{PH}$ domain of wild-type Vav3 is essential for AR activation by mutagenesis analysis $(34,35)$. Since point mutation of the PH domain may inactivate nuclear localization signal (NLS) in the PH domain, this finding implicates a potential role of Vav3 as a coactivator for AR. Alternatively, mutation in the PH domain may impact on PIP3 binding, which will implicate that cell membrane association is essential for Vav3 function in upregulation of AR activity.

Mutagenesis analysis reveals that deletion of the $\mathrm{DH}$ domain abolishes the constitutive active Vav3 for AR activation. On the other hand, Vav3 mutants with deletion of the $\mathrm{SH} 2$ and $\mathrm{SH} 3$ domains at the C-terminus or deletion of the $\mathrm{CH}$ and $\mathrm{AD}$ domains at the $\mathrm{N}$-terminus show an elevated ability for AR activation. The truncated Vav3 protein including only $\mathrm{DH}$ and $\mathrm{PH}$ domains shows the most potent activity for AR activation at both basal level and in response to DHT and EGF stimulation. These studies suggest that the DH and PH domains of Vav3 are sufficient for regulation of AR activity and additional phosphorylation sites in addition to the tyrosines in the $\mathrm{AD}$ domain are subjected to regulation of Vav3 activity via the various signaling pathways. 
Previous studies revealed that Vav1 presents the component of transcriptionally active nuclear factor of activated $\mathrm{T}$ cells (NFAT)- and nuclear factor (NF)кB-like complexes, indicating its role as a transcription coregulator (44). We identified the nucleus localization signal in the $\mathrm{PH}$ domain of Vav3 by homologous analysis (39). The current study showed that Vav3 is localized in the cytoplasm and sometimes to a lesser extent in the nucleus in prostate cancer cells. This finding suggests that Vav3 may function as both coactivator and signaling molecule in prostate cancer cells.

Receptor protein tyrosine kinases, such as EGFR and PDGFR, bind and activate Vav protein $(5,51,54,55)$. However, the detailed signaling pathway of Vav3 leading to elevated genomic and non-genomic AR activity in the context of EGFR/HER2-PI3K-Akt pathway has not been elucidated. Specifically, it is not clear how Vav3-AR complex interacts with EGFR and other signaling molecules, such as PI3K p85 and p110 subunits. Vav3 has been demonstrated to interact with EphA2 receptor upstream of the kinase domain in the receptor cytoplasmic domain $(54,56)$, while it interacts with EGFR at the autophosphorylation site downstream of the kinase domain (55). Furthermore, the kinase domain of EphA2 interacts with PI3K p85 subunit. It appears that both Vav3 and PI3K anchor at the cytoplasmic domain of RPTK. The detailed signaling pathway in the context of EGFR/ HER2-Vav3-AR-PI3K-Akt in prostate cancer cells remains to be determined.

In summary, this study adds to our understanding on the role of Vav3 in upregulation of AR activity and androgenindependent growth in prostate cancer. The Vav3-mediated pathway provides a promising target for the rational development of novel therapies against prostate cancer and androgenindependent disease.

\section{Acknowledgements}

This study was supported by grants from Ohio Cancer Research Associates and NIH R01CA119935.

\section{References}

1. Bustelo XR: Regulatory and signaling properties of the Vav family. Mol Cell Biol 20: 1461-1477, 2000.

2. Bustelo XR: Vav proteins, adaptors and cell signaling. Oncogene 20: 6372-6381, 2001.

3. Katzav S, Martin-Zanca D and Barbacid M: Vav, a novel human oncogene derived from a locus ubiquitously expressed in hematopoietic cells. EMBO J 8: 2283-2290, 1989.

4. Zugaza JL, Lopez-Lago MA, Caloca MJ, Dosil M, Movilla N and Bustelo XR: Structural determinants for the biological activity of Vav proteins. J Biol Chem 277: 45377-45392, 2002.

5. Moores SL, Selfors LM, Fredericks J, et al: Vav family proteins couple to diverse cell surface receptors. Mol Cell Biol 20: 6364-6373, 2000.

6. Aghazadeh B, Lowry WE, Huang XY and Rosen MK: Structural basis for relief of autoinhibition of the Dbl homology domain of proto-oncogene Vav by tyrosine phosphorylation. Cell 102: 625-633, 2000.

7. Taplin ME and Balk SP: Androgen receptor: a key molecule in the progression of prostate cancer to hormone independence. J Cell Biochem 91: 483-490, 2004.

8. Heinlein CA and Chang C: Androgen receptor in prostate cancer. Endocr Rev 25: 276-308, 2004.

9. Grossmann ME, Huang $\mathrm{H}$ and Tindall DJ: Androgen receptor signaling in androgen-refractory prostate cancer. J Natl Cancer Inst 93: 1687-1697, 2001.
10. Burnstein KL: Regulation of androgen receptor levels: implications for prostate cancer progression and therapy. J Cell Biochem 95: 657-669, 2005.

11. Lara PNJ and Meyers FJ: Treatment options in androgenindependent prostate cancer. Cancer Invest 17: 137-144, 1999.

12. Beedassy A and Cardi G: Chemotherapy in advanced prostate cancer. Semin Oncol 26: 428-438, 1999.

13. Taplin ME, Bubley GJ, Shuster TD, et al: Mutation of the androgen-receptor gene in metastatic androgen-independent prostate cancer. N Engl J Med 332: 1393-1398, 1995.

14. Visakorpi T, Hyytinen E, Koivisto $\mathrm{P}$, et al: In vivo amplification of the androgen receptor gene and progression of human prostate cancer. Nat Genet 9: 401-406, 1995.

15. Koivisto P, Kononen J, Palmberg C, et al: Androgen receptor gene amplification: a possible molecular mechanism for androgen deprivation therapy failure in prostate cancer. Cancer Res 57: 314-319, 1997.

16. Hobisch A, Culig Z, Radmayr C, Bartsch G, Klocker H and Hittmair A: Distant metastases from prostatic carcinoma express androgen receptor protein. Cancer Res 55: 3068-3072, 1995.

17. Veldscholte J, Ris-Stalpers C, Kuiper GG, et al: A mutation in the ligand binding domain of the androgen receptor of human LNCaP cells affects steroid binding characteristics and response to antiandrogens. Biochem Biophys Res Commun 173: 534-540, 1990.

18. Kokontis J, Ito K, Hiipakka RA and Liao S: Expression and function of normal and $\mathrm{LNCaP}$ androgen receptors in androgeninsensitive human prostatic cancer cells. Altered hormone and antihormone specificity in gene transactivation. Receptor 1: 271-279, 1991.

19. McKenna NJ and O'Malley BW: Combinatorial control of gene expression by nuclear receptors and coregulators. Cell 108: 465-474, 2002.

20. Gregory CW, He B, Johnson RT, et al: A mechanism for androgen receptor-mediated prostate cancer recurrence after androgen deprivation therapy. Cancer Res 61: 4315-4319, 2001.

21. Fujimoto N, Mizokami A, Harada S and Matsumoto T: Different expression of androgen receptor coactivators in human prostate. Urology 58: 289-294, 2001.

22. Culig Z, Comuzzi B, Steiner H, Bartsch G and Hobisch A: Expression and function of androgen receptor coactivators in prostate cancer. J Steroid Biochem Mol Biol 92: 265-271, 2004.

23. Wen Y, Hu MC, Makino K, et al: HER-2/neu promotes androgenindependent survival and growth of prostate cancer cells through the Akt pathway. Cancer Res 60: 6841-6845, 2000.

24. Rochette-Egly C: Nuclear receptors: integration of multiple signalling pathways through phosphorylation. Cell Signal 15: 355-366, 2003.

25. Tremblay A, Tremblay GB, Labrie F and Giguere V: Ligandindependent recruitment of SRC-1 to estrogen receptor beta through phosphorylation of activation function AF-1. Mol Cell 3: 513-519, 1999.

26. Yeh S, Lin HK, Kang HY, Thin TH, Lin MF and Chang C: From HER2/Neu signal cascade to androgen receptor and its coactivators: a novel pathway by induction of androgen target genes through MAP kinase in prostate cancer cells. Proc Natl Acad Sci USA 96: 5458-5463, 1999.

27. Guo Z, Dai B, Jiang T, et al: Regulation of androgen receptor activity by tyrosine phosphorylation. Cancer Cell 10: 309-319, 2006.

28. Unni E, Sun S, Nan B, et al: Changes in androgen receptor nongenotropic signaling correlate with transition of LNCaP cells to androgen independence. Cancer Res 64: 7156-7168, 2004.

29. Migliaccio A, Di Domenico M, Castoria G, et al: Steroid receptor regulation of epidermal growth factor signaling through Src in breast and prostate cancer cells: steroid antagonist action. Cancer Res 65: 10585-10593, 2005.

30. Freeman MR, Cinar B and Lu ML: Membrane rafts as potential sites of nongenomic hormonal signaling in prostate cancer. Trends Endocrinol Metab 16: 273-279, 2005.

31. Lu ML, Schneider MC, Zheng Y, Zhang X and Richie JP: Caveolin-1 interacts with androgen receptor. A positive modulator of androgen receptor mediated transactivation. J Biol Chem 276: 13442-13451, 2001

32. Haas D, White SN, Lutz LB, Rasar M and Hammes SR: The modulator of nongenomic actions of the estrogen receptor (MNAR) regulates transcription-independent androgen receptormediated signaling: evidence that MNAR participates in G protein-regulated meiosis in Xenopus laevis oocytes. Mol Endocrinol 19: 2035-2046, 2005. 
33. Dong ZY, Liu Y, Lu S, et al: Vav3 oncogene is overexpressed and regulates cell growth and androgen receptor activity in human prostate cancer. Mol Endocrinol 20: 2315-2325, 2006.

34. Lyons LS, Rao S, Balkan W, Faysal J, Maiorino CA and Burnstein KL: Ligand-independent activation of androgen receptors by Rho GTPase signaling in prostate cancer. Mol Endocrinol 22: 597-608, 2008.

35. Lyons LS and Burnstein KL: Vav3, a rho GTPase guanine nucleotide exchange factor, increases during progression to androgen independence in prostate cancer cells and potentiates androgen receptor transcriptional activity. Mol Endocrinol 5: 1061-1072, 2006.

36. Liu Y, Mo JQ, Hu Q, et al: Targeted overexpression of Vav3 oncogene in prostatic epithelium induces nonbacterial prostatitis and prostate cancer. Cancer Res 68: 6396-6406, 2008.

37. Rau KM, Kang HY, Cha TL, Miller SA and Hung MC: The mechanisms and managements of hormone-therapy resistance in breast and prostate cancers. Endocr Relat Cancer 12: 511-532, 2005.

38. Levenson AS, Catherino WH and Jordan VC: Estrogenic activity is increased for an antiestrogen by a natural mutation of the estrogen receptor. J Steroid Biochem Mol Biol 60: 261-268, 1997.

39. Lee K, Liu Y, Mo JQ, Zhang J, Dong Z and Lu S: Vav3 oncogene activates estrogen receptor and its overexpression may be involved in human breast cancer. BMC Cancer 8: 158, 2008.

40. Lu S, Tsai SY and Tsai MJ: Melecular mechanisms of androgenindependent growth of human prostate cancer LNCaP-AI cells. Endocrinology 140: 5054-5059, 1999.

41. Zhang J, Kalkum M, Yamamura S, Chait BT and Roeder RG: E protein silencing by the leukemogenic AML1-ETO fusion protein. Science 305: 1286-1289, 2004

42. Zhang J, Kalkum M, Chait BT and Roeder RG: The N-CoRHDAC3 nuclear receptor corepressor complex inhibits the JNK pathway through the integral subunit GPS2. Mol Cell 9: 611-623, 2002

43. Burd CJ, Petre CE, Morey LM, et al: Cyclin D1b variant influences prostate cancer growth through aberrant androgen receptor regulation. Proc Natl Acad Sci USA 103: 2190-2195, 2006.

44. Houlard M, Arudchandran R, Regnier-Ricard F, et al: Vav1 is a component of transcriptionally active complexes. J Exp Med 195: $1115-1127,2002$
45. Movilla N and Bustelo XR: Biological and regulatory properties of Vav-3, a new member of the Vav family of oncoproteins. Mol Cell Biol 19: 7870-7885, 1999.

46. Fan S, Gao M, Meng Q, et al: Role of NF-kappaB signaling in hepatocyte growth factor/scatter factor-mediated cell protection. Oncogene 24: 1749-1766, 2005.

47. Vandermoere F, El Yazidi-Belkoura I, Adriaenssens E, Lemoine $\mathrm{J}$ and Hondermarck $\mathrm{H}$ : The antiapoptotic effect of fibroblast growth factor-2 is mediated through nuclear factorkappaB activation induced via interaction between Akt and IkappaB kinase-beta in breast cancer cells. Oncogene 24: 5482-5491, 2005.

48. Gong L, Li Y, Nedeljkovic-Kurepa A and Sarkar FH: Inactivation of NF-kappaB by genistein is mediated via Akt signaling pathway in breast cancer cells. Oncogene 22: 4702-4709, 2003.

49. Zhuang L, Lin J, Lu ML, Solomon KR and Freeman MR: Cholesterol-rich lipid rafts mediate akt-regulated survival in prostate cancer cells. Cancer Res 62: 2227-2231, 2002.

50. Freeman MR, Cinar B, Kim J, et al: Transit of hormonal and EGF receptor-dependent signals through cholesterol-rich membranes. Steroids 72: 210-217, 2007.

51. Zeng L, Sachdev P, Yan L, et al: Vav3 mediates receptor protein tyrosine kinase signaling, regulates GTPase activity, modulates cell morphology, and induces cell transformation. Mol Cell Biol 20: 9212-9224, 2000.

52. Sachdev P, Zeng L and Wang LH: Distinct role of phosphatidylinositol 3-kinase and Rho family GTPases in Vav3-induced cell transformation, cell motility, and morphological changes. J Biol Chem 277: 17638-17648, 2002.

53. Lopez-Lago M, Lee H, Cruz C, Movilla N and Bustelo XR: Tyrosine phosphorylation mediates both activation and downmodulation of the biological activity of Vav. Mol Cell Biol 20: 1678-1691, 2000.

54. Hunter SG, Zhuang G, Brantley-Sieders D, Swat W, Cowan CW and Chen $\mathrm{J}$ : Essential role of Vav family guanine nucleotide exchange factors in EphA receptor-mediated angiogenesis. Mol Cell Biol 26: 4830-4842, 2006.

55. Tamas P, Solti Z, Bauer P, et al: Mechanism of epidermal growth factor regulation of Vav2, a guanine nucleotide exchange factor for Rac. J Biol Chem 278: 5163-5171, 2003.

56. Fang WB, Brantley-Sieders DM, Hwang Y, Ham AJ and Chen J: Identification and functional analysis of phosphorylated tyrosine residues within EphA2 receptor tyrosine kinase. J Biol Chem 283: 16017-16026, 2008. 